\title{
Publisher Correction: Nfat/calcineurin signaling promotes oligodendrocyte differentiation and myelination by transcription factor network tuning
}

\author{
Matthias Weider ${ }^{1}$, Laura Julia Starost ${ }^{2,3}$, Katharina Groll ${ }^{2}$, Melanie Küspert ${ }^{1}$, Elisabeth Sock ${ }^{1}$, Miriam Wedel ${ }^{1}$, \\ Franziska Fröb ${ }^{1}$, Christian Schmitt ${ }^{1}$, Tina Baroti ${ }^{1}$, Anna C. Hartwig ${ }^{1}$, Simone Hillgärtner ${ }^{1}$, Sandra Piefke ${ }^{1}$, \\ Tanja Fadler ${ }^{1}$, Marc Ehrlich ${ }^{2,3}$, Corinna Ehlert ${ }^{2}$, Martin Stehling ${ }^{3}$, Stefanie Albrecht ${ }^{2}$, Ammar Jabali², \\ Hans R. Schöler ${ }^{3}$, Jürgen Winkler ${ }^{4}$, Tanja Kuhlmann² \& Michael Wegner (D ${ }^{1}$
}

Correction to: Nature Communications https://doi.org/10.1038/s41467-018-03336-3; published online 02 March 2018

The originally published version of this Article omitted Tanja Kuhlmann and Michael Wegner as jointly supervising authors. This has now been corrected in both the PDF and HTML versions of the Article.

Published online: 23 April 2018

Open Access This article is licensed under a Creative Commons Attribution 4.0 International License, which permits use, sharing, adaptation, distribution and reproduction in any medium or format, as long as you give appropriate credit to the original author(s) and the source, provide a link to the Creative Commons license, and indicate if changes were made. The images or other third party material in this article are included in the article's Creative Commons license, unless indicated otherwise in a credit line to the material. If material is not included in the article's Creative Commons license and your intended use is not permitted by statutory regulation or exceeds the permitted use, you will need to obtain permission directly from the copyright holder. To view a copy of this license, visit http://creativecommons.org/licenses/by/4.0/.
\end{abstract}

(C) The Author(s) 2018

\footnotetext{
${ }^{1}$ Institut für Biochemie, Emil-Fischer-Zentrum, Friedrich-Alexander-Universität Erlangen-Nürnberg, D-91054 Erlangen, Germany. ${ }^{2}$ Institute of Neuropathology, University Hospital Münster, D-48149 Münster, Germany. ${ }^{3}$ Department of Cell and Developmental Biology, Max Planck Institute for Molecular Biomedicine, D-48149 Münster, Germany. ${ }^{4}$ Department of Molecular Neurology, University Hospital Erlangen, Friedrich-Alexander-Universität Erlangen-Nürnberg, D-91054 Erlangen, Germany. These authors contributed equally: Matthias Weider, Laura Julia Starost and Katharina Groll. These authors jointly supervised this work: Tanja Kuhlmann, Michael Wegner. Correspondence and requests for materials should be addressed to

T.K. (email: Tanja.Kuhlmann@ukmuenster.de) or to M.W. (email: michael.wegner@fau.de)
} 